\title{
The metro in Algiers: user profile and quality of service
}

\author{
J. de Oña ${ }^{1}, T$. Baouni ${ }^{2} \&$ R. de Oña ${ }^{1}$ \\ ${ }^{1}$ TRYSE Research Group, Department of Civil Engineering, \\ University of Granada, Spain \\ ${ }^{2}$ Laboratoire VUDD, \\ Ecole Polytechnique d'Architecture et Urbanisme, Algeria
}

\begin{abstract}
In recent years, rail transit modes (metros, trams and light rail systems) have been greatly developed around the world. They are used as a way of promoting quality public transport, to encourage modal shift from private vehicles and to achieve sustainable mobility in cities. Algiers is the first city in the Maghreb that has implemented an underground metro. The metro came into operation in November 2011. This mode of transport, whose operation is well known in developed countries, is fairly new to the population of Algiers. For this reason, the results of mobility and quality studies conducted in other developed countries cannot be extrapolated to countries like Algeria, or other neighbouring countries where other rail transit projects are being developed. The first survey on mobility and quality of service in the Algiers' metro took place in June 2012. The survey collected information on: socio-demographic characteristics of users, mobility habits, overall satisfaction with the subway, and satisfaction with 16 specific characteristics of the service (frequency, punctuality, cleanliness, price, etc.). This article presents some of the results of that survey, identifying the user profile that is most prevalent in this mode of transport as well as the users' perceptions of the quality of service provided. The results show that the level of satisfaction with almost all the characteristics of the service is very high, except for the price. Finally, the survey also revealed that, for the moment, the objective of encouraging a modal shift from private vehicles has not been achieved, because this kind of user represents only $15 \%$ of the total metro's users.

Keywords: service quality, subway of Algiers, user profile.
\end{abstract}




\section{Introduction}

The first metro line was opened in London in 1890. Since then, more than 100 conurbations in Europe, America, Asia and the Middle East and North Africa have joined the ranks of cities with their own metro system. Metropolitan railways are urban, electric transport systems with high capacity and a high frequency of service. They are totally independent from other traffic, roads or pedestrians. So, they have to be designed in tunnel, viaducts or on surface level but with physical separation. These kinds of systems are the optimal public transport mode for a high capacity network service. However, they require very high investments costs [1].

Because of their high costs, in recent years, Light Rail Transit (LRT) systems have started to be developed greatly around the world. The term LRT covers those systems whose role and performance lie between a tramway running on the highway at one extreme and an urban heavy rail or underground metropolitan railway at the other [1]. However, LRT systems are usually an electric rail-borne form of transport which is operated partially on its own right-of-way. Probably the main difference, if any, between a tramway and a LRT system is the "segregated right-of-way". The reserved space at ground level separates the LRT from private vehicles but enables level-crossing with pedestrians and other traffic. This right-of-way increases its speed and regularity [2].

Today, there are approximately 400 LRT systems in operation worldwide, with constructions in some 60 more cities and plans in more than 200 cities. Europe is the densest LRT continent, with 170 systems in operation and nearly 100 more in construction or planned. North America (30 in operation, 10 in construction) and Asia are also very active in opening new systems [3]. Table 1 shows the number of systems and lines in operation in Europe (in 2004) for metro systems and for LRT systems. It is possible to see the predominance of LRT systems in Europe over the metro systems.

Table 1: $\quad$ LRT and metro systems in Europe [3].

\begin{tabular}{|l|c|c|c|c|c|c|}
\hline & \multicolumn{3}{|c|}{ LRT systems } & \multicolumn{3}{c|}{ Metro systems } \\
\cline { 2 - 7 } & No. & Lines & $\begin{array}{c}\text { Track length } \\
(\mathbf{k m})\end{array}$ & No. & Lines & $\begin{array}{c}\text { Track length } \\
(\mathbf{k m})\end{array}$ \\
\hline EU-15 & 107 & 448 & $4,793(59 \%)$ & 27 & 117 & $2,072(88 \%)$ \\
\hline New Member States & 30 & 349 & $2,240(28 \%)$ & 3 & 7 & $93(4 \%)$ \\
\hline Beyond EU-25 & 33 & 144 & $1,027(13 \%)$ & 6 & 14 & $181(8 \%)$ \\
\hline Total & $\mathbf{1 7 0}$ & $\mathbf{9 4 1}$ & $\mathbf{8 , 0 6 0}$ & $\mathbf{3 6}$ & $\mathbf{1 3 8}$ & $\mathbf{2 , 3 4 6}$ \\
\hline
\end{tabular}

Traditionally, both systems were considered an opportunity for sustainable development in urban environments. They were considered a tool for promoting quality public transport, to encourage modal shift from private vehicles and to achieve a sustainable mobility in cities. However, in the last years they are also becoming an urban structuring tool around which mobility policy is developed $[4,5]$, and a key factor in improving quality of life [1]. 
In the North of Africa there are various countries (e.g. Algeria, Morocco and so on) that have started to build metros and LRT systems. Particularly, Algeria is focusing on guided modes of transport (i.e. metro, LRT, funicular and cable railway) for promoting a sustainable mobility in its main cities (e.g. Algiers, Oran, Constantine, Batna, Setif, Tlemcen, Blida, Bejaia, Djelfa, and so on) [6].

In the particular case of Algiers, in the last year a metro and a LRT system have come into operation. The metro was selected as part of the development and expansion of the urban agglomeration. The metro has been chosen to be one of the public transport modes for effectively contributing to solve the problem of displacements, on the one hand, and to develop the land use, on the other hand [7].

This mode of transport, whose operation is well known in other developed countries, is fairly new to the population of Algiers. For this reason, the results of mobility and quality studies conducted in other countries cannot be extrapolated to Algeria. The first survey on mobility and quality of service in the Algiers' metro in June 2012 took place. The survey collected information on: sociodemographic characteristics of users, mobility habits, overall satisfaction with the metro, and satisfaction with 16 specific characteristics of the service (frequency, punctuality, cleanliness, price, etc.).

This article presents some of the results of that survey, identifying the user profile that is most prevalent in this mode of transport as well as the users' perception of the quality of service provided.

\section{The metro in Algiers}

The first city in the Maghreb (the second in North Africa, after Cairo) that has implemented an underground metro system is Algiers. The first metro line in Algiers came into operation in November 2011. Originally, the design studies advocated for the construction of a metro consisting on three lines accounting for a track length of $56 \mathrm{~km}$. For financial capacity and technical reasons, only one metro line from the Haï El Badr to Grande Poste (9.5 km with 10 stations) is fully completed [7]. Figure 1 shows that there are three line extensions projected for the future.

The Algiers metro runs between 5:00 AM to 11:00 PM with a 5 minutes average frequency. Its maximum speed is $70 \mathrm{~km} / \mathrm{h}$. Siemens France, Vinci and CAF, who won the contract through an international tender, built the metro line. The French-owned company RATP-El Djazaïr operates the system. The regular tickets cost 50 dinars (about 0.50 euro), although the cost of each journey is reduced to 35 dinars if passengers buy a monthly travel pass.

Between November $1^{\text {st }} 2011$ and October $31^{\text {st }}$ 2012, the metro transported around 13 million passengers (approximately 35,000 passengers per day). The stations that show a higher daily demand as the origin of the trips are Grande Poste, Haï El Badr, Les Fusillés and $1^{\mathrm{er}} \mathrm{Mai}$, and those that have the highest demand as the destination of the trips are Grande Poste, Haï El Badr, $1^{\mathrm{er}}$ Mai, Les Fusillés and Khalifa Boukhalfa [9]. 


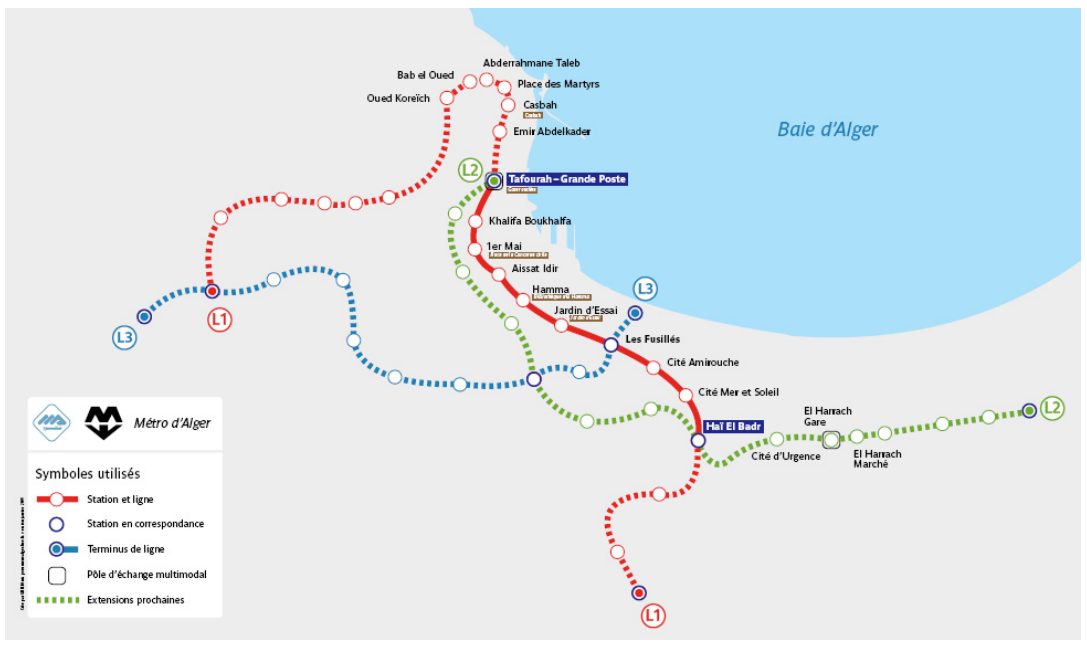

Figure 1: $\quad$ Algiers metro network [8].

\section{General description of the survey on the Algiers' metro line}

In June 2012, the Laboratoire Ville Urbanisme et Development Durable (VUDD) from the Ecole Polytechnique d'Architecture et Urbanisme (EPAU) in Algiers carried out the first survey on mobility and quality of service in the Algiers' metro line. 214 personal interviews were conducted on board.

The questionnaire was structured into two main sections. Through the first section, data concerning socio-economic characteristics (e.g. gender, age and occupation), and travel habits (e.g. trip purpose and frequency, access time and mode, and transport mode used before the metro came into operation) were collected. The second section was specific about passengers' perception of the metro service: users expressed satisfaction rates, using a 4-point likert scale, about 15 service quality factors concerning service, cleanliness, comfort, safety and information; and also they expressed their overall satisfaction with the metro line. The survey included a specific question about the price, which used a 3point likert scale. Table 2 shows the categories of socio-economic variables, travel habits and quality variables.

\section{Results}

\subsection{User profile}

Figure 2 shows the main socio-economics characteristics of the users. The sample is made up more of men (56.1\%) than females (43.9\%). Most of the passengers are aged between 36 and 59 years old (35.5\%), followed by passengers with 25 to 35 years old (33.6\%) and passengers with 18 to 24 years old (24.8\%). The old passengers (more than 59 years old) represent a very small part of the sample (only 6.1\%). 
Table 2: Categories of socio-economic characteristics, travel habits and quality attributes.

\begin{tabular}{|c|c|}
\hline Variable & Categories \\
\hline Gender & 1. Women; 2. Men \\
\hline Age & 1. $\{18-24\} ; 2 .\{25-35\} ; 3 .\{36-59\} ; 4 .\{>59\}$ \\
\hline Occupation & $\begin{array}{l}\text { 1. Worker; 2. Artisans, traders or other low level } \\
\text { professionals; } 3 \text {. Medium level professionals; } 4 . \\
\text { High level professionals; } 5 . \text { Employed; } 6 \text {. Retired; } \\
\text { 7. Unemployed; } 8 \text {. Students }\end{array}$ \\
\hline Travel reason & $\begin{array}{l}\text { 1. Professional; 2. Visit; 3. Shopping or services; } 4 . \\
\text { Leisure; 5. Studies }\end{array}$ \\
\hline Use frequency & 1. Daily; 2. Weekly; 3. Monthly \\
\hline $\begin{array}{l}\text { Access time to the metro } \\
\text { station (minutes) }\end{array}$ & Numerical \\
\hline $\begin{array}{l}\text { Complementary modes from } \\
\text { origin to the metro station }\end{array}$ & $\begin{array}{l}\text { 1. Walking; 2. Bus; 3. Car; 4. Several modes; } 5 . \\
\text { Taxi; 6. Train }\end{array}$ \\
\hline $\begin{array}{l}\text { Mode of transport used before } \\
\text { the metro entered in operation }\end{array}$ & $\begin{array}{l}\text { 1. Walking; 2. Bus; 3. Car; 4. Several modes; } 5 . \\
\text { Taxi; 6. Train }\end{array}$ \\
\hline $\begin{array}{l}\text { Service quality attributes and } \\
\text { overall satisfaction }\end{array}$ & $\begin{array}{l}\text { 1. Very dissatisfied; 2.Dissatisfied; 3.Satisfied; } \\
\text { 4.Very satisfied }\end{array}$ \\
\hline Ticket price & 1. Very expensive; 2 . Reasonable; 3 . Not expensive \\
\hline
\end{tabular}

Most of the metro users (63.1\%) are employed (including all the employment categories: workers, artisans, traders or other level professionals, medium level professionals, high level professionals and employed without identification of the level) or students (22.9\%). However, it is significant that the number of metro users increases when the level of studies (from workers or low level professionals to high level professionals) increases. This may be related to the price of the ticket.

The main travel reason is professional reason (37.4\%). However, there are other travel reasons also very important: visit (20.6\%), shopping or services $(18.7 \%)$ and leisure $(15.0 \%)$. In this case, studies reasons are the lowest ones (only $8.4 \%$ ). This fact allows identifying that the students (22.9\% of the sample) do not use the metro only for studies reasons (mainly for leisure and visit). The frequency of use is distributed more or less equally between the three categories: $35.1 \%$ daily, $31.3 \%$ weekly and $33.6 \%$ monthly.

Most of the users access to the metro line walking (41.1\%) or by bus (24.3\%). There are also another important number of users $(16.4 \%)$ that use several different transport modes to access the metro line. The proportion of users that access the metro line with their own car $(9.8 \%)$ or using a taxi $(7.9 \%)$ is not very high. And finally, the number of users that access the metro using the train is negligible (only 0.5\%). This may be because this metro line is not well connected to the train stations. The intermodality between metro and train has not been achieved. 

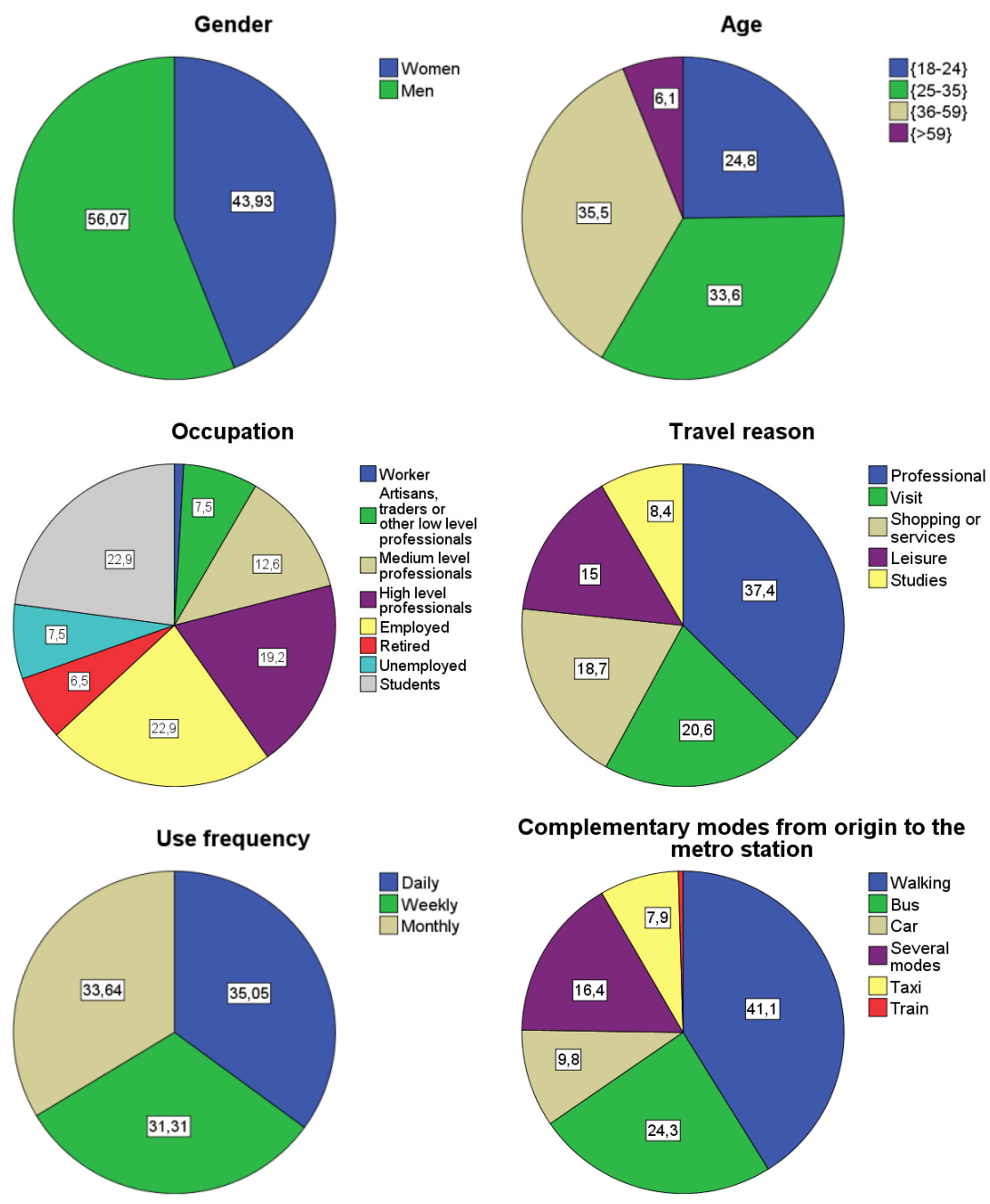

Figure 2: $\quad$ User profile.

It is important to point out that a very high number of users (59.9\%) have to use one or more motorized vehicles (bus, car, taxi or train) to access the metro line. This is in accordance with the fact that the average access time to the metro line is 25.15 minutes (with s.d. 29.42 minutes). Figure 3 shows that, even most of the population (around 70\%) has an access time below 20 minutes, 10\% of users present access times over one hour. 


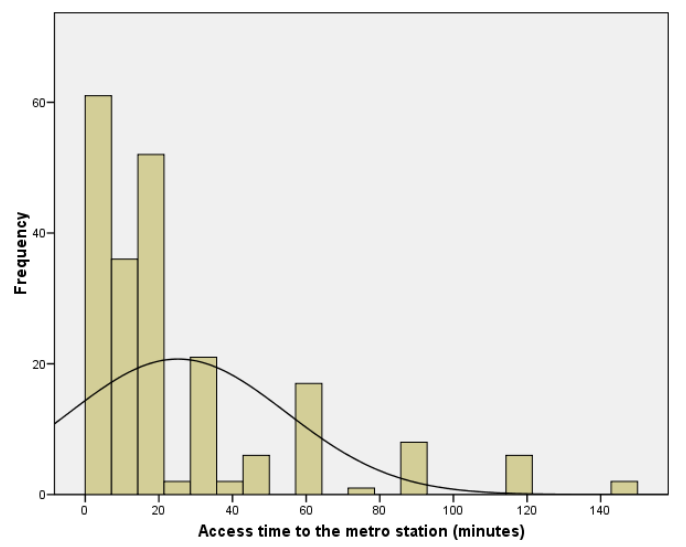

Figure 3: Access time to the metro station histogram.

Based on the previous results, it could be point out that one of the main metro's users is an employed male with an age between 25 and 59 years old, which use this transport mode for professional reasons and access the metro line on foot.

\subsection{Modal shift}

As it was previously pointed out, usually, one of the main reasons for building a metro line is to improve the quality of service of the public transport modes, to encourage modal shift from private vehicles and to promote a sustainable mobility in cities. In the case of the metro of Algiers, Figure 4 shows that the new users of the metro line mainly come from the bus services, several modes of transport and the taxi service. So, it seems that the metro has improved the

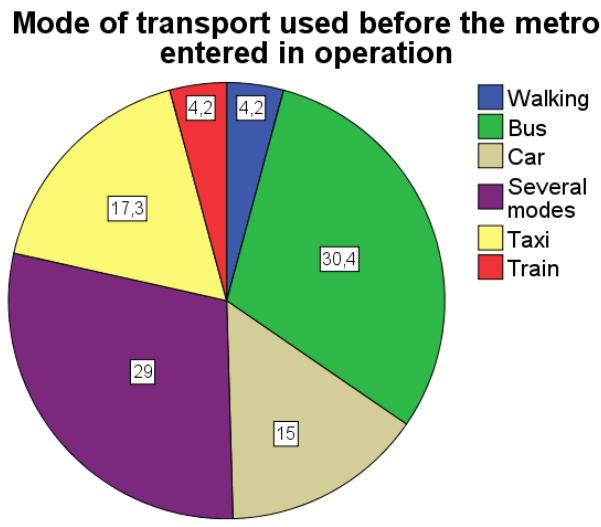

Figure 4: Modal shift when the metro came into operation. 
quality of service with regard to other public transport modes, promoting a modal shift from those others public modes.

However, only $15 \%$ of the new metro's users come from the private vehicle. So, for the moment, the metro line has not promoted a modal shift from private to public transport modes in order to achieve a sustainable mobility in Algiers. These results could be based on the following reasons:

- the survey was developed after only eight months of metro's operation;

- for the moment, the metro network is only one line, so its effects on mobility are very limited; or,

- the metro line is not well connected to others transport modes.

\subsection{Quality of service perception}

The users are very satisfied with the overall quality of service (3.54 in a 4-point likert scale) of the metro line. This was expected due to the low quality of service of all the others public transportation modes (bus, train, taxi, etc.).

Regarding each one of the service quality attributes, Table 3 shows that the satisfaction rate for all of them is also over 3 points (i.e. between satisfied and very satisfied, see Table 2), except for the ticket price with a satisfaction rate of 1.50 (i.e. between very expensive and reasonable). This is normal because the price of the ticket is 50 dinars ( 0.50 euros). This price, which could be considered cheap in any EU-15 European country (with GDP per capita over $\$ 30,000$ ), is very expensive in Algeria, with a GDP per capita of $\$ 7,200$ (GDPs estimated 2011).

Apart from the ticket price, the four service quality attributes with the lowest rates are station arrangement (3.03); information at stations (3.37), evening service (from 20:00 to 23:00) (3.37) and course of the line (3.41). This is also understandable given that:

- for the moment, the stations are almost empty (there are no restaurants, shops, information services, etc.);

- the frequency of the service is significantly reduced during the evening; and,

- as there is only one line, each user has his own preferences about the course of the line depending on his own residence location or working place.

The four service quality attributes with the highest satisfaction rates are the punctuality of runs (3.87), the frequency of runs (3.84), the air-conditioning on board (3.82) and the cleanliness on board (3.79). This is also understandable given that the main quality standards (i.e. frequency, punctuality, safety, airconditioning, cleanliness, etc.) of the Algiers metro line are comparable to most advanced metro networks in Europe or around the world. However, the quality of the others public transportation modes and the traffic supported by the private and public vehicles operating along the Algerians freeways and highways is not comparable (see Figure 5). 
Table 3: $\quad$ Satisfaction rates.

\begin{tabular}{|l|l|r|}
\hline Aspect & Service quality attribute & Satisfaction rate \\
\hline \multirow{3}{*}{ Safety } & Security on board & 3.65 \\
\cline { 2 - 3 } & Security at stations & 3.67 \\
\hline \multirow{4}{*}{ Comfort } & Cleanliness on board & 3.79 \\
\cline { 2 - 3 } & Cleanliness and accessibility of stations & 3.65 \\
\cline { 2 - 3 } & Noise on board & 3.45 \\
\cline { 2 - 3 } & Vehicles' equipment meets the passengers' & 3.57 \\
\cline { 2 - 3 } & need & \\
\cline { 2 - 3 } & Air-conditioning on board & 3.82 \\
\cline { 2 - 3 } & Ticket price* & 1.50 \\
\cline { 2 - 3 } & Frequency of runs & 3.84 \\
\cline { 2 - 3 } & Punctuality of runs & 3.87 \\
\cline { 2 - 3 } & Weekend and holydays services & 3.65 \\
\cline { 2 - 3 } & Evening service (from 20h00 to 23h00) & 3.37 \\
\hline Information & Information at stations & 3.37 \\
\hline Convenience & Course of the line & 3.41 \\
\cline { 2 - 3 } & Length of the displacement & 3.77 \\
\hline Other & Stations arrangement & 3.03 \\
\hline & Overall level of satisfaction with the service & 3.54 \\
\hline
\end{tabular}

* The ticket price uses a 3-point likert scale. All the others attributes use a 4-point likert scale.

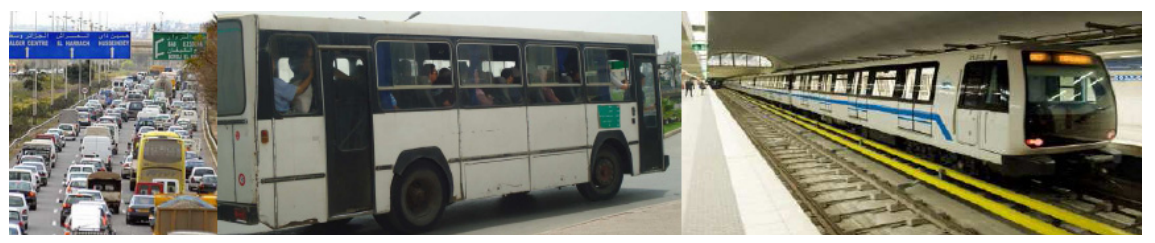

Figure 5: Several transport modes in Algiers (private vehicle, bus, and metro).

\section{Conclusions}

The Algiers' metro has substantially improved the public transport network of this city. The inauguration of this mode of transport in November 2011 was an important event for the Algerian population, who observed how its city was becoming the first city of the Maghreb and the second one of Africa (after of Cairo) in having an underground metro in operation. Moreover, few months later a LRT line also came into operation. The establishment of these guided systems is not an isolated initiative for the Algerian capital, but they are part of the infrastructure transport policy developed by the Algerian Government, as reveals the construction and project of other lines of LRT systems in many cities in Algeria. With this type of actions the Algerian Government is evidently focusing on a sustainable mobility. 
The survey's results about mobility and quality of service presented in this paper allow extracting a set of conclusions that can be relevant for future decisions, regarding the public transport services in Algiers:

- In general, the metro's users are very satisfied with the overall performance of the line. We can observe very high satisfaction rates in all the attributes considered, except the Price of the ticket that is considered to be very high.

- A modal shift has been produced from other public transport modes (bus, taxi or train) to the metro line. However, the users' modal shift from the private vehicle has not been significant (under 15\%).

- The user typology that predominates is a middle age man that access to the metro on foot and uses it for professional reasons.

Despite to the unquestionable improvement the new infrastructure has created in the public transport of Algiers, as the quality of service survey's results show, this action (construction of the metro and the LRT system) will only be useful to promote a modal shift from the private vehicle and reach a sustainable mobility if other complementary actions, that affect the rest of the public and private transport systems, are developed. These other actions should focus on improving the rest of public transport modes, contributing to the intermodality and limiting the use of the private vehicle. It is necessary that these types of policies, that are completely known and assumed, in other developed countries, should be also implemented in countries as Algeria and its neighborhoods.

In order to generalize these results, it is important to have caution because the sample size of this survey is reduced (only 214 users), and the survey was conducted only eight months after the metro line came into operation.

\section{Acknowledgements}

We would like to thanks the Spanish Agency for International Development Cooperation (AECID) that funded the Preparatory Action AP/037312/11 and the Conserjería de Innovación, Ciencia y Economía of the Junta de Andalucía (Spain) (Excellence Research Project P08-TEP-381). The funding obtained through these projects make possible this work. The authors also acknowledge the VUDD students for the survey that made available the data for this study.

\section{References}

[1] UITP. (2013). International Association of Public Transport web page (http://www.uitp.org/). Last accessed on February 21 2013.

[2] De Oña, J., Calvo, F.J., Garach, L., De Oña, R., López, G. (2010). How to expand subway and urban railway networks: Light rail extensions in Madrid, Spain, Transportation Research Record, 2146, pp. 10-17. http://dx.doi.org/10.3141/2146-02.

[3] ERRAC. (2004). Light Rail and Metro Systems in Europe: Current Market, Perspectives and Research Implication, European Rail Research Advisory Council, Brussels, Belgium, 26p. 
[4] Calvo, F., de Oña, J., Arán, F. (2013) Impact of the Madrid subway on population settlement and land use, Land Use Policy, 31, pp. 627-639. http://dx.doi.org/10.1016/j.landusepol.2012.09.008.

[5] Calvo, F., de Oña, J., Arán, F., Nash, A. (2013). The light rail transit experience in Madrid: effects on population settlement and land use, Transportation Research Record, in press.

[6] Baouni, T., de Oña, J. (2012). Los proyectos de tranvías en las principales ciudades Argelinas: desafíos e impactos urbanos, Proceedings of the 10th Transport Engineering Conference, Granada, Spain, June 20-22, 2012.

[7] Baouni, T. (2009). Le transport collectif urbain dans la ville d'Alger: un service public à la recherche de son adaptation, Vies de Villes, 12, pp. 3437.

[8] Berchache, R. (2009). Le métro d'Alger, quelles attentes pour la ville ?, Vies de Villes, 12, pp. 50-54.

[9] EMA, BETUR. (2102). Enquête fréquentation Métro d'Alger, Alger, Mars 2012, 25p. 